\title{
RESPONSABILIDADE SOCIAL DO PROGRAMA EMPRESA SAUDÁVEL E QUALIDADE DE VIDA EM UMA OPERADORA DE PLANOS DE SAÚDE DE FLORIANÓPOLIS
}

\author{
P. Souza', K.S. Coelho ${ }^{2}$, A.F. Kanitz ${ }^{3}$, H. S. Gonçalves ${ }^{2}$ e A.C.K. A. Bispo ${ }^{2}$ \\ ${ }^{1}$ Universidade do Vale do Itajaí, ${ }^{2}$ Universidade Federal da Paraíba; ${ }^{3}$ Universidade Federal de Santa Catarina \\ E-mail: priscila.de.souza@hotmail.com; kellen.coelho@hotmail.com; amarildofelipekanitz@gmail.com; \\ helenmep@gmail.com; kruta@terra.com.br
}

Artigo submetido em julho/2013 e aceito em novembro/2013

\section{RESUMO}

No âmbito de uma operadora de planos de saúde de Florianópolis, foi analisada a relação entre a responsabilidade social de um programa chamado Empresa Saudável e a qualidade de vida dos seus empregados, por meio de estudo de caso predominantemente qualitativo com finalidade descritiva. Durante um mês, entrevistas semiestruturadas com 15 empregados de diferentes diretorias da operadora foram gravadas e transcritas na íntegra. No que tange às subcategorias de análise, a responsabilidade social com o público interno foi examinada por meio dos indicadores do Instituto Ethos e, a qualidade de vida no trabalho, por meio dos atributos propostos pelo modelo teórico de Walton.
O entrelaçamento dos dados a respeito dessas subcategorias revelou duas coerências e quatro incoerências. Uma das coerências refere-se ao fato de que a valorização da diversidade e o compromisso com a equidade racial e de gênero estão consoantes com a subcategoria integração social. Por outro lado, notou-se que embora a empresa estabeleça uma relação salutar com os empregados terceirizados, acaba por comprometer o constitucionalismo. A responsabilidade social com o público interno e a qualidade de vida dos empregados mostraram-se satisfatórias; porém, foram averiguadas fragilidades a serem ajustadas, em favor da sincronia entre responsabilidade e qualidade no contexto da organização ora analisada.

PALAVRAS-CHAVE: responsabilidade social, qualidade de vida no trabalho, público interno.

\section{SOCIAL RESPONSIBILITY OF THE HEALTHY COMPANY PROGRAM AND QUALITY OF LIFE IN A HEALTH INSURANCE OPERATOR FROM FLORIANÓPOLIS}

\begin{abstract}
Considering a health insurance operator from Florianópolis, the relation between the social responsibility of a program called Healthy Company and the quality of life of its employees was analyzed through case study, predominantly qualitative with descriptive purpose. During a month, semi-structured interviews with 15 employees from different boards of the operator were taped and entirely transcribed. Regarding the subcategories of analysis, social responsibility towards the internal public was examined through the indicators of the Ethos Institute and the quality of working life through the attributes proposed by Walton. The interlacing of data concerning these
\end{abstract}

subcategories revealed two coherences and four incoherencies. One of the coherences refers to the fact that the valuing of diversity and the commitment to racial and gender equality are consonant with the social integration subcategory. On the other hand, it was noted that although the company establishes a salutary relationship with the outsourced employees, it ultimately compromises the constitutionalism. The social responsibility towards the internal public and the quality of life of employees showed to be satisfactory. However, fragilities were verified to be adjusted in favor of synchrony between responsibility and quality in the context of the organization herein analyzed.

KEYWORDS: social responsibility. quality of work life. internal public. 


\section{RESPONSABILIDADE SOCIAL DO PROGRAMA EMPRESA SAUDÁVEL E QUALIDADE DE VIDA EM UMA OPERADORA DE PLANOS DE SAÚDE DE FLORIANÓPOLIS}

\section{A GÊNESE DA IDEIA}

No decorrer dos anos, sobretudo a partir dos anos oitenta do século passado, começaram a emergir questionamentos sobre a adoção de práticas tradicionais em um cenário organizacional que estava se modificando intensamente. Inquietações sobre divisão do trabalho, hierarquia e determinados mecanismos de controle organizacional deram origem a estudos mais pluralísticos, que se remetiam diretamente à pós-modernidade (ou modernidade tardia), reconhecida por certos estudiosos como uma era pós-industrial (pós-fordista) pautada no modelo de acumulação flexível e na redução da burocratização das organizações, contrariando princípios delineados por Weber, que se baseavam na racionalização do mundo (REED, 1992). Contudo, o que se tem constatado é que até mesmo as novas teorias administrativas têm sido tributárias das antigas escolas da Administração, sendo que se persiste na manutenção das harmonias administrativas e do ethos burocrático (PAULA, 2002).

Nesse sentido, a expressão "responsabilidade social", que tem sido considerada um dos ícones em termos de novas formas de gestão por muitos autores, também é passível de contestações acerca de seu modo de concepção e de sua efetiva essência.

Os valores pós-econômicos são evidenciados na exigência pública de que as organizações se preocupem com o desempenho social e não apenas com o econômico. Desse modo, a sobrevivência da empresa em um ambiente competitivo está condicionada a como a estratégia empresarial lida com essas variáveis, de modo a se alcançar eficiência e lucratividade com a preservação da imagem e da reputação das companhias no mercado e sociedade, sendo imprescindível a agregação de valor social ao negócio (TENÓRIO, 2004). Porém, o que se evidencia, em muitos casos, é um paradoxo entre os seus ditames a efetiva prática, que, por sua vez, acaba por ser dominada por preceitos funcionalistas e teleológicos de organizar (MISOCZKI, 2010).

Embora vários estudos priorizem a responsabilidade social exercida frente ao seu público externo, ela atua também no contexto do seu público interno - empregados e gestores. Supostamente, torna-se imprescindível crer que a responsabilidade social voltada ao público interno tenha uma relação coerente com a qualidade de vida dos seus trabalhadores. Corroborando essa ideia, o Instituto Ethos (2009) ressalta que a construção de um ambiente de trabalho benéfico e favorável à prática profissional das pessoas apresenta-se como ato da responsabilidade social.

Sob essa linha de pensamento, foi possível abordar a realidade de uma operadora de planos de saúde florianopolitana, cuja prática de responsabilidade social tem sido expressivamente reconhecida por meio de prêmios nacionais nos últimos anos. Atualmente, ela desenvolve o Programa Empresa Saudável, que atua em seis eixos distintos voltados à promoção da qualidade de vida dos seus trabalhadores: vida light, monitoramento, alimentação saudável, atividade física, saber viver e responsabilidade socioambiental (POLÍTICA, 2010).

Tendo em vista que muitos autores apresentam definições que sobrepõem os conceitos de responsabilidade socioambiental e de responsabilidade social, julgou-se interessante realizar um estudo a respeito da prática de responsabilidade social confrontando-a com uma perspectiva de 
análise sobre a qualidade de vida no trabalho, uma vez que essas duas categorias são preceitos da missão da empresa em estudo. Posto isso, buscou-se conhecer a percepção dos empregados da empresa sobre a responsabilidade social com o público interno; identificar como está a qualidade de vida no trabalho dos empregados; e apontar as coerências e incoerências constatadas nessa relação.

\section{A RESPONSABILIDADE SOCIAL NO CONTEXTO ORGANIZACIONAL}

A abordagem da responsabilidade social empresarial surgiu no início do século $X X$, com o filantropismo. Em seguida, com a exaustão do modelo industrial e o desenvolvimento da sociedade pós-industrial, o conceito evoluiu passando a agrupar as aspirações de agentes sociais no plano de negócios das corporações. Além do filantropismo, desenvolveram-se conceitos como voluntariado empresarial, cidadania corporativa, responsabilidade social corporativa, e, por último, desenvolvimento sustentável (TENÓRIO, 2006).

Durante muito tempo, a questão da ética nos negócios foi considerada de pouca importância, assunto favorito de religiosos, justificando-se que no universo empresarial nem sempre é possível tomar decisões com a nitidez do certo e errado, prever e decidir quem será beneficiado ou prejudicado (KARKOTLI, 2008).

Até o princípio do século XX o objetivo principal das organizações era a obtenção de lucros para seus acionistas - ética e responsabilidade social eram interesses apenas do Estado. Ashley (2005) exemplifica alguns casos ilustrativos, como o caso "A.P. Smith Manufacturing Company versus Barlow", no qual a Suprema Corte de Nova Jersey, em 1953, foi favorável à inserção da referida corporação na sociedade, determinando que uma corporação possa buscar o desenvolvimento social e estabelecendo em lei a filantropia corporativa, contrariando alguns dos acionistas. A partir disso, surgiram diversos defensores da prioridade da ética e da responsabilidade social sobre os retornos financeiros de uma empresa.

Karkotli (2006) discorre que, a partir da segunda metade do século XX, iniciou-se um processo de mudança no gerenciamento das empresas, motivado por alterações que ocorreram na sociedade mundial no âmbito político, econômico, tecnológico, ambiental e social, de forma que outros fatores, além dos econômico-financeiros, passaram a ser divulgados.

$\mathrm{Na}$ História houve autores como Friedman (1970), que argumentava contra a responsabilidade social declarando que a empresa possui, como propósito único, a composição dos negócios e o retorno financeiro aos acionistas. Inclusive os motivos éticos ou a ideia de praticar algo além da maximização dos lucros foram considerados inapropriados. Em perspectiva contrária, Frederick (1960) expandiu o conceito de responsabilidade social, assegurando que o uso de recursos, tanto humanos quanto econômicos, possui desígnios sociais, não se limitando somente aos interesses dos integrantes da empresa.

Tais mudanças se intensificaram a partir dos anos sessenta nos Estados Unidos e no princípio da década de setenta na Europa, quando a sociedade passou a exigir um comportamento socialmente responsável por parte dos gestores empresariais, fato que consolidou a necessidade de divulgação dos balanços sociais (TREVISAN, 2002). Apesar dessa mobilização mundial, segundo dados do Instituto Ethos (2009), na conjuntura brasileira foi apenas na década de noventa que o movimento de valorização da responsabilidade social 
empresarial teve um significativo impulso, devido à ação de entidades não governamentais, institutos de pesquisa e empresas sensíveis à questão. Gomes e Moretti (2007) narram que esse movimento ocorreu com rapidez notável, avanço que foi registrado pelos meios de comunicação que a ele deram atenção privilegiada, colaborando para sua difusão.

O debate acerca da responsabilidade social corporativa tem ocupado espaços relevantes de discussão no cenário mundial, realçando as diversas facetas e perspectivas adotadas pelas organizações (FREIRE; SOUZA; FERREIRA, 2008). Se por um lado há autores como Karkotli (2006) e Veloso (2005), que apresentam a responsabilidade social organizacional como uma forma de contribuir com o crescimento e desenvolvimento da sociedade, por outro também é possível encontrar autores como Churchill e Peter (2000), que a entendem como uma moderna estratégia de marketing.

Garay (2001) alerta para o fato de que o conceito de responsabilidade social pode ser entendido como a alternativa dos empresários, conscientemente adotada, de investir taticamente no campo social. Diferindo-se, assim, a responsabilidade social da filantropia, pois esta concebe um tipo de investimento social associado à caridade, ao paternalismo ou ao legítimo assistencialismo. Corroborando essa afirmação, Melo Neto e Froes (2001) acrescentam que a organização que possui responsabilidade social é aquela que difunde novos valores que restabelecem a solidariedade social, a coerência social e a obrigação social com a equidade, a dignidade e a liberdade, a democracia e a melhoria da qualidade de vida de todos que vivem na sociedade.

Melo Neto e Froes (1999) também apresentam os vários escopos da responsabilidade social de uma organização, a saber: apoio ao desenvolvimento da comunidade onde atua; preservação do meio ambiente; investimento no bem-estar dos empregados e seus dependentes; ambiente de trabalho agradável; comunicações transparentes; retorno aos acionistas; sinergia com os parceiros; satisfação dos clientes e/ou consumidores. As organizações que adotam essas práticas de responsabilidade social vão ao encontro com o citado por Veloso (2005), que afirma que atualmente as empresas precisam ir além das suas responsabilidades econômicas e legais, atentando às suas responsabilidades éticas, morais e sociais. Nesse sentido, um dos mais expressivos desafios pode ser a responsabilidade social no âmbito de seu público interno.

No entendimento de Karkotli (2008), o ambiente interno das organizações é composto por empregados e dirigentes que fornecem capacidade de trabalho, empenho, fidelidade e esforço físico e intelectual para as empresas. A noção de que as organizações possuem responsabilidade com seu público interno faz com que autores como Melo Neto e Froes (1999) defendam que além da empresa desenvolver ações de responsabilidade social com foco na comunidade onde se encontra situada, precisa também focalizar ações em seu público interno, seus empregados e dependentes. O desígnio é motivá-los a um excelente desempenho, instituir um ambiente agradável de trabalho e colaborar para o seu bem-estar. Com isso a empresa recebe dedicação, empenho e lealdade de seus empregados, e ainda obtém ganhos em produtividade. A empresa que atua nessas duas dimensões adquire o status de "empresa cidadã" (ASHLEY, 2005).

Quando as pessoas trabalham para uma organização que acreditam ser justa, no qual todos estão dispostos a dar de si para a concretização das tarefas, onde comportamentos que denotam fidelidade, honestidade e zelo são marcantes, elas trabalham em um nível mais elevado 
(KARKOTLI, 2008). Tanto a responsabilidade social interna quanto a externa possuem igual importância e devem estar sempre interconectadas e, desse modo, o desenvolvimento de um programa de responsabilidade social externa precisa ser respaldado por um vasto apoio de toda a organização. O envolvimento do quadro de empregados em um programa de responsabilidade social empresarial externa explicita compromisso social e fortalece a conexão do empregado com a organização, pois o processo intensifica uma identificação do indivíduo com os valores da organização, que deixa de ser entendida somente como empregadora e passa a ser percebida como um agente ativo que contribui para a sociedade da qual faz parte (DIAS, 2007). Mediante a preocupação em controlar os mecanismos organizativos promotores de responsabilidade social, uma série de gestores tem se utilizado dos indicadores que as organizações adotam nessa área.

A transparência das ações empresariais tem sido consoante com a configuração atual dos mercados, tendo em vista a expressiva quantidade de códigos de ética, de conduta, e princípios e técnicas de auditoria criados por instituições que primam por padrões de medição de ações e resultados. Esses padrões foram desenvolvidos por meio de modelos que avaliam e expressam informações inicialmente designadas financeiras, mas que, com o decorrer dos anos, ganharam a esfera ambiental e social (PONTES, 2007).

Os indicadores de responsabilidade social são os instrumentos que a organização pode empregar para direcionar suas estratégias, e também para avaliar a eficácia das metas e as iniciativas projetadas para a parceria e mudança do seu entorno. Do mesmo modo com que se acompanha e avalia as estratégias e práticas empresariais para concorrência e lucratividade, também se julga fundamental, por meio dos indicadores, identificar as necessidades e apontar as deficiências das iniciativas de responsabilidade social (KARKOTLI, 2008).

Os indicadores de responsabilidade social corporativa são sistemas de avaliação que possibilitam às empresas a constatação do seu nível de envolvimento com questões sociais. Além de auxiliar a administração, os indicadores permitem a comunicação transparente da organização com seus múltiplos agentes. Dessa forma, as corporações reforçam sua convenção com a ética nos negócios e com o melhoramento da qualidade de vida da sociedade. Atualmente, os indicadores de responsabilidade social corporativa mais empregados pelas empresas são o balanço social, a demonstração do valor adicionado e as certificações de responsabilidade social (TENÓRIO, 2006). Com o intuito de auxiliar as empresas a avaliar seu nível de envolvimento com iniciativas nesse âmbito, algumas instituições elaboram modelos de indicadores, a saber: Global Compact, Balanço Social, Indicadores Ethos e Indicadores de Hopkins. Como base para este estudo, foram eleitos os Indicadores Ethos de Responsabilidade Social Empresarial, pois seus parâmetros e diretrizes convergem com os aplicados pela operadora de planos de saúde investigada, conforme segue descrito.

Os Indicadores Ethos de Responsabilidade Social Empresarial podem ser delineados como uma ferramenta de avaliação e gestão das práticas de responsabilidade social no posicionamento estratégico da organização. Conforme o Instituto Ethos (2009), tais indicadores são instrumentos de aprendizado e de avaliação da gestão, tratando-se de uma ferramenta de uso essencialmente interno, sendo aplicados como um utensílio de autoavaliação. Eles estão distribuídos em sete grandes temas: valores, transparência e governança; público interno; meio ambiente; fornecedores; consumidores e clientes; comunidade; governo e sociedade (KARKOTLI, 2008).

Por ser objeto deste estudo, convém apresentar os indicadores do tema público interno, que são: relações com sindicatos; relações com trabalhadores terceirizados; gestão participativa; 
compromisso com o futuro das crianças; compromisso com o desenvolvimento infantil; valorização da diversidade; compromisso com a equidade racial; compromisso com a equidade de gênero; política de remuneração, benefícios e carreira; cuidado com saúde, segurança e condições de trabalho; compromisso com o desenvolvimento profissional e a empregabilidade; comportamento frente a demissões; preparação para aposentadoria.

À luz desses indicadores, torna-se possível confrontar o desempenho da organização com o desempenho das demais organizações do seu segmento, analisando os aspectos potenciais da gestão e as oportunidades de melhoria em favor de uma responsabilidade social digna de assim ser designada.

\section{A QUALIDADE DE VIDA NO TRABALHO}

Desde o início de sua existência, a qualidade de vida tem sido uma preocupação do homem, e, mesmo com outros títulos e em outras conjunturas, está sempre voltada a facilitar ou ocasionar satisfação e bem-estar ao trabalhador na execução de sua tarefa (RODRIGUES, 2008). Walton (1973), um dos pesquisadores precursores da sistematização dos critérios e conceitos da qualidade de vida no trabalho, a define como algo além dos ordenamentos da legislação trabalhista, surgido na entrada do século XX com a regulamentação do trabalho de menores, da jornada de trabalho e descanso semanal, e das indenizações por acidentes de trabalho.

Os anos sessenta foram o palco de uma convulsão social. Trabalhadores norte-americanos com suas reivindicações e estudantes franceses não passivos foram marcos dessa fase que repercutiu diretamente no interior das organizações, acarretando crises e conflitos no meio organizacional. Essa realidade tornou o indivíduo mais consciente e favoreceu o surgimento dos estudos denominados "qualidade de vida no trabalho". Porém, somente na década seguinte, com uma mudança no foco gerencial, surgiram as primeiras aplicações estruturadas e sistematizadas no interior da organização utilizando a qualidade de vida no trabalho (RODRIGUES, 2008).

Na percepção de Corrêa (1993), qualidade de vida no trabalho é um fenômeno complexo que vem sendo revelado pouco a pouco, fazendo-se necessário o estudo do contexto socioeconômico para compreensão dos seus valores e motivações predominantes. A autora apresenta quatro estágios para o entendimento da qualidade de vida no trabalho: o primeiro é baseado no marxismo e nas políticas trabalhistas e sociais, e compreende as condições de sustento como salário compatível com a função, segurança, prevenção de acidentes, seguridade social e aposentadoria; o segundo estágio refere-se a incentivos salariais, participação nos lucros e eficiência administrativa, com destaque às ideias de Taylor e Fayol no movimento de produtividade e de engenharia industrial; o terceiro estágio surgiu a partir dos trabalhos da escola de Relações Humanas enfatizando o reconhecimento social, a liderança democrática, o treinamento, a participação e a moral de grupo; e, por fim, o quarto estágio é caracterizado pela autorrealização e surge com as teorias comportamentais e o movimento de qualidade de vida no trabalho, ampliando as teses de autodesenvolvimento, criatividade, flexibilidade no horário de trabalho, grupos pequenos e meio ambiente.

No entendimento de Walton (1973), a expressão "qualidade de vida" é empregada com crescente frequência para apresentar certos valores ambientais e humanos, negligenciados pela sociedade industrial em benefício do avanço tecnológico, da produtividade e do crescimento 
econômico. A qualidade de vida no trabalho apresenta-se como uma forma de humanizar as relações na organização, sustentando uma ligação estreita com a produtividade e, sobretudo, com a satisfação do trabalhador no seu ambiente de trabalho. Institui-se, além disso, em condição de vida no trabalho agregada ao bem-estar, à saúde e à segurança do trabalhador (BÚRIGO, 1997).

Apesar do contexto organizacional de busca por produtividade e em meio a métodos de mudança com a finalidade de aperfeiçoar seu posicionamento competitivo no mercado, Albuquerque (1992) entende que a qualidade de vida no trabalho vem ganhando espaço como valor essencial das práticas de competitividade congruente com o bem-estar organizacional. Souza e Bastos (2009) concluem ensinando que o bem-estar do trabalhador, em todas as suas dimensões, torna-se, então, uma das condições fundamentais para que o indivíduo desenvolva o seu potencial como profissional.

Diversos métodos com o propósito de humanizar as relações de trabalho foram desenvolvidos por estudiosos, proporcionando um nível mais elevado de satisfação, motivação e qualidade de vida no ambiente profissional. Entre os modelos existentes, destacam-se os de dimensões básicas da tarefa de Hackman e Oldhan (1975); as quatro dimensões de qualidade de vida no trabalho de William Westley (1979); o de Nadler e Lawer (1983); o modelo de Siqueira e Coletta (1989); e os propostos por Walton (1973).

Ao analisar esses modelos e suas respectivas subcategorias, foi possível pontuar e definir o método a ser empregado neste estudo. Assim, mesmo ciente das críticas tecidas ao modelo de Walton decorrentes da sua tradução para a Língua Portuguesa, optou-se pela adoção do método, de forma adaptada. 0 método de Walton foi eleito por contemplar um número significativo de categorias, permitir uma relação entre os diferentes atributos analisados e, além disso, considerar a contingencialidade temporal. Seu modelo de qualidade de vida no trabalho foi desenvolvido por meio de pesquisas, observações e entrevistas com a finalidade de identificar os fatores e dimensões que afetam de maneira mais significativa o trabalhador na conjuntura de seu labor (VIEIRA, 1996). Em síntese, Walton definiu estas oito (8) categorias conceituais para aferir as características notáveis da qualidade de vida no trabalho: compensação justa e adequada; condições de trabalho; uso e desenvolvimento de capacidades; oportunidade de crescimento e segurança; integração social na organização; constitucionalismo; trabalho e espaço total de vida; e relevância social do trabalho na vida (RODRIGUES, 2008). Tais categorias merecem uma breve explanação, como segue.

No entendimento de Milkovich e Boudreau (2000), o desenvolvimento profissional é a educação que visa a expandir, desenvolver e aprimorar o homem para o seu crescimento profissional no exercício de sua carreira dentro da organização, ou para que se amplie sua eficiência e produtividade. Objetiva proporcionar conhecimentos ao indivíduo e prepará-lo para eventuais exigências em cargo futuro, e é fornecido por organizações ou empresas especializadas em desenvolvimento pessoal. Entretanto, em algumas organizações, na verdade o treinamento tem sido um ferrenho mecanismo de controle (ROCKENBACH JÚNIOR et al, 2013).

Dutra (2009) cita que o desenvolvimento das pessoas está diretamente ligado ao desenvolvimento de suas carreiras, haja vista que a carreira é uma sequência de cargos ocupados ao longo da trajetória profissional do indivíduo. Considerando que as organizações também são responsáveis pela administração da carreira dos seus empregados, seria coerente que fornecessem todas as condições e suportes necessários para estes realizarem escolhas 
adequadas e serem bem-sucedidos, pois os empregados necessitam de orientação da empresa para conhecer quais passos e direções deverão adotar para o desenvolvimento de suas carreiras dentro ou fora dela.

Um fator que também se mostra importante é o reconhecimento e valorização do empregado, especialmente por meio de remuneração (MARRAS, 2005). Além do salário, há de se considerar ainda os benefícios que podem ser agregados em forma de componentes de remuneração variável, tais como adicionais, horas extras, gratificações, bônus e comissões.

Outro fator a ser abordado são as condições de trabalho oferecidas pela organização. No entendimento de Walton (1973), as condições de trabalho englobam aquelas relacionadas à qualidade de vida dos empregados. Ele propõe sugestões para sua melhoria apontando a necessidade de horários razoáveis, reforçados por um período habitual de trabalho unificado, bem como condições físicas que reduzam ao mínimo o risco de doenças e danos à saúde. Gil (2001) alerta que garantir elevados níveis de segurança e condições físicas adequadas para a realização do trabalho e de garantia de saúde para os empregados é uma forma de a organização manter constantemente os custos baixos.

A respeito da integração social dentro da organização, Vieira (1996) entende ser fundamental analisar a existência de igualdade de oportunidades e de senso comunitário, bem como a ausência de preconceitos e discriminação. A inexistência de diferenças hierárquicas excessivas, a franqueza interpessoal e a ausência de preconceitos são fatores extremamente essenciais para que a empresa tenha um bom nível de integração social. Walton (1973) estabelece alguns aspectos essenciais para uma integração social adequada no trabalho. Inicialmente, apresenta a necessidade de ausência de preconceitos de cor, raça, sexo, religião, nacionalidade, estilo de vida e aparência física. A ausência de estratificação e mobilidade social promoveria ou induziria um senso de comunidade nas organizações, o que seria o grande propulsor para um nível adequado de integração social.

A subcategoria constitucionalismo refere-se à garantia do respeito aos direitos dos trabalhadores por parte da organização e pode ser investigada por meio de quatro critérios: cumprimento dos direitos legais do trabalhador; privacidade pessoal; liberdade de expressão; e normas e rotinas (FERNANDES, 1996).

Quanto à perspectiva trabalho e espaço total de vida, Walton (1973) ensina que está relacionada com a mensuração do equilíbrio entre a vida pessoal do empregado e sua vida no trabalho. O autor define ainda que a experiência de trabalho de um indivíduo pode ter consequência positiva ou negativa sobre outros campos de sua vida, tais como suas relações familiares. Isso é corroborado pelo pensamento de Ramos (1989), pautado na necessidade de se considerar o indivíduo na sua multidimensionalidade.

O último fator contemplado é a relevância social da vida no trabalho, fator este que possui extrema importância por estar altamente relacionado com os objetivos desta pesquisa. Esta categoria, na lição de Walton (1973), propende aferir a qualidade de vida no trabalho por meio da percepção dos empregados acerca da responsabilidade social da organização com a comunidade, serviços prestados e atendimento aos seus empregados. O autor define alguns critérios a serem analisados, entre eles: imagem da instituição, que mensura a visão do empregado quanto à organização e sua satisfação em participar desta; responsabilidade social da instituição, que mensura a visão do empregado quanto às ações da organização na comunidade; responsabilidade social pelos serviços, critério relacionado à percepção do empregado sobre a 
qualidade dos serviços oferecidos à comunidade; e, como último critério, a responsabilidade social pelos empregados, que está relacionada com a percepção do empregado quanto à sua valorização e participação na organização.

Contudo, percebe-se a importância das organizações definirem modelos de qualidade de vida no trabalho adequados à sua realidade e que sejam passíveis de aplicação prática. E foi com base nessa lógica que buscou-se analisar a relação existente entre responsabilidade social e qualidade de vida dos empregados no cerne da operadora de saúde ora pesquisada.

\section{OS PROCEDIMENTOS METODOLOÓGICOS}

Neste estudo de caso predominantemente qualitativo com finalidade descritiva a população da pesquisa abrangeu os empregados da operadora de planos de saúde de Florianópolis, que, segundo dados da organização, totalizam atualmente oitocentos e cinquenta e seis (856) empregados. Portanto, como não é possível envolver toda a população na coleta de dados, adotou-se uma técnica de amostragem intencional, em que os elementos que formaram a amostra relacionavam-se intencionalmente de acordo com determinadas características constituídas no plano e nas questões de pesquisa estabelecidas pelos pesquisadores.

Nesse sentido, foram escolhidos propositadamente quinze (15) empregados de diferentes diretorias, a fim de que assim fosse possível um maior conhecimento da percepção dos empregados acerca da responsabilidade social da organização, bem como a influência desta na qualidade de vida daqueles. Optou-se também por adotar um fechamento amostral por saturação teórica, que consistiu na suspensão de inclusão de novos participantes quando os dados obtidos passaram a apresentar, na avaliação das pesquisadoras, certa redundância, não sendo mais considerada relevante a persistência na coleta de dados (DENZIN; LINCOLN, 1994).

Foram entrevistados dois (2) supervisores e um (1) assistente da diretoria de serviços próprios, um (1) assistente e um (1) analista da diretoria estratégica, um (1) assistente da diretoria comercial e marketing, dois (2) assistentes da diretoria administrativa e financeira, um (1) líder e seis (6) assistentes da diretoria de rede prestadora. Com o intuito de preservar a identidade dos empregados entrevistados, estes foram chamados apenas de participantes (P) e numerados de 1 a 15.

Os dados secundários foram obtidos junto ao site da organização, livros, revistas, artigos, materiais eletrônicos e, também, documentos institucionais disponibilizados a uma das pesquisadoras, que compõe o quadro de empregados da organização em questão. Dessa maneira, foi possível consultar a intranet e o manual de orientações internas e procedimentos sistêmicos. Já os dados primários foram obtidos por meio da realização de entrevistas semiestruturadas, cuja técnica foi eleita para dar maior fluidez e permitir que dados além dos contemplados pela figura do entrevistador pudessem emergir do campo. Também foi adotada a técnica de observação direta via checklist.

As entrevistas semiestruturadas foram conduzidas por um roteiro com questões abertas que permitiram captar o ponto de vista dos participantes da pesquisa, de modo que os pesquisadores não predeterminaram sua perspectiva por meio de uma seleção antecedente de classe de questões (ROESCH, 1999). Antes da realização das entrevistas foi aplicado um pré-teste com dois (2) assistentes da diretoria de rede prestadora e não foi identificado algum tipo de 
dificuldade de interpretação em nenhum dos questionamentos abordados. Após, foram realizadas entrevistas com os demais participantes, aplicadas durante o período de trabalho destes, em horários previamente agendados. Ao iniciar cada entrevista, explanou-se a finalidade da pesquisa e explicou-se o compromisso firmado com o anonimato dos participantes. Em seguida, solicitou-se permissão para a gravação das entrevistas. Essa conversa proporcionou um clima confiável que favoreceu a obtenção de alguns dados dos quais não se tinha nem suposições. As entrevistas foram aplicadas durante um mês e tiveram duração média de uma (1) hora cada, todas transcritas na íntegra.

Para análise da responsabilidade social interna da operadora de planos de saúde foram adotados os Indicadores Ethos de Responsabilidade Social Empresarial abordando o tema público interno. Já quanto à categoria qualidade de vida no trabalho, foram adotadas subcategorias propostas por Walton (1973). Ao zelar pela cientificidade deste estudo, julgou-se viável sintetizar os quesitos utilizados para investigar as categorias responsabilidade social com público interno e qualidade de vida no trabalho, conforme feito no quadro 1.

Quadro 1 - Categorias e subcategorias de análise

\begin{tabular}{|l|l|}
\hline \multicolumn{1}{|c|}{$\begin{array}{c}\text { RESPONSABILIDADE SOCIAL } \\
\text { COM PÚBLICO INTERNO }\end{array}$} & \multicolumn{1}{c|}{$\begin{array}{c}\text { QUALIDADE DE VIDA } \\
\text { NO TRABALHO }\end{array}$} \\
\hline - Relações com sindicatos; & - Oportunidade de crescimento e \\
- Relações com trabalhadores terceirizados; & segurança; \\
- Gestão participativa; & Compensação justa e adequada; \\
- Compromisso com o futuro das crianças; & - Uso e desenvolvimento de capacidades; \\
- Compromisso com o desenvolvimento infantil; & - Integração social na organização; \\
- Valorização da diversidade; & Constitucionalismo; \\
- Compromisso com a equidade racial; & - Trabalho e espaço total de vida; \\
- Compromisso com a equidade de gênero; & Relevância social do trabalho na vida. \\
- Política de remuneração, benefícios e carreira; & \\
- Cuidado com saúde, segurança e condições de trabalho; & \\
- Compromisso com o desenvolvimento profissional e a & \\
\hline - empregabilidade; & \\
\hline Preparação para aposentadoria. & \\
\hline
\end{tabular}

Fonte: Instituto Ethos (2009) e Walton (1973).

De posse da transcrição das entrevistas, os dados foram tratados de forma categorial, por meio do agrupamento dos trechos do texto nas categorias e subcategorias mencionadas. Após a compilação dos dados, estes foram analisados e confrontados com o referencial teórico (BARDIN, 2009).

\section{A APRESENTAÇÃO E ANÁLISE DOS DADOS}

Tendo em vista que o objetivo primordial deste estudo é analisar a relação entre a responsabilidade social e a qualidade de vida no trabalho na operadora de planos de saúde pesquisada, definiu-se esta ordem para a apresentação dos dados: Programa Empresa Saudável e eixo responsabilidade socioambiental; responsabilidade social; qualidade de vida no trabalho; e coerências e incoerências identificadas. 


\section{O Programa Empresa Saudável}

Empresa Saudável é um programa institucional criado na operadora de planos de saúde em questão em maio de 2008, com o objetivo de modificar comportamentos na vida dos empregados, a fim de promover e instigar a prática de promoção à saúde, bem como a integração dos empregados no desenvolvimento de ações que visam ao bem-estar e ao aperfeiçoamento da qualidade de vida.

Atrelado ao Departamento de Gestão de Pessoas, o programa também conta com a contribuição de diferentes áreas da organização e constitui-se de seis eixos, contemplando diferenciadas atividades: vida light, monitoramento da saúde, atividade física, alimentação saudável, saber viver e responsabilidade socioambiental.

Neste estudo, as inquietações iniciais direcionaram o foco para o eixo responsabilidade socioambiental, que promove ações direcionadas para o envolvimento dos empregados com o seu entorno, visando a proporcionar conexão com o bem-estar coletivo e ambiental, sendo algumas de suas atividades: consumo consciente, campanhas solidárias, voluntariado empresarial e doação de sangue e medula óssea (POLÍTICA..., 2010).

\section{A responsabilidade social com o público interno}

Os indicadores da categoria responsabilidade social com o público interno foram adaptados do tema público interno e dos Indicadores Ethos de Responsabilidade Social Empresarial, tendo em vista que é modelo adotado pela organização para medir o desempenho de seus programas e ações de responsabilidade socioambiental.

No que diz respeito à relação da classe patronal com o sindicato da categoria, a maioria dos entrevistados comentou que este não consegue intermediar os interesses dos empregados com os da organização de maneira eficaz, talvez por se tratar de um sindicato da área da saúde, onde a maioria dos empregados são funcionários públicos. As palavras de P2, "Acredito que o sindicato deveria ouvir os colaboradores, analisar o interesse dos mesmos e depois negociar com a empresa", refletem que os entrevistados, apesar de reconhecerem a importância do sindicato, consideram que este deveria atentar mais aos interesses dos empregados e à realidade da organização antes das negociações empresa-sindicato, o que é corroborado por Karkotli (2008).

Quando indagados a relação da organização com trabalhadores terceirizados, a maioria dos entrevistados considerou que a organização estabelece uma boa relação com os empregados terceirizados, oferecendo em diversas situações condições de trabalho semelhantes aos empregados da própria organização, o que em determinadas situações pode gerar uma insatisfação nestes, abalando a essência da noção de uma empresa cidadã, conforme designa Ashley (2005).

Existe uma condição de trabalho muito parecida com as dos colaboradores, principalmente no que diz respeito ao relacionamento interpessoal. Em alguns casos pontuais, existe até certo "exagero", ou seja, o terceirizado chega a se confundir com um colaborador, em virtude do tempo de prestação de serviço e seguir muitas ordens diretas do representante da Cooperativa. (P1) 
Os participantes da pesquisa acreditam que a gestão organizacional cede espaço à participação. A fala de P9 é um exemplo disso: "Geralmente nas reuniões que são realizadas temos oportunidade de dar sugestões de melhorias nos processos, na solução de problemas que estão acontecendo, ou seja, é bem participativa". Mas diante da observação direta, verificou-se que a participação mais acentuada encontra-se nos espaços operacionais, sendo as decisões estratégicas assumidas, de forma mais restritiva, pelos gestores, contrapondo-se aos preceitos do Instituto Ethos (2009).

Sobre a valorização da diversidade, a maior parte dos participantes mencionou que a organização oferece igualdade de oportunidades em termos de recrutamento, acesso a treinamento, remuneração, avaliação ou promoção de seus empregados independentemente de sexo, raça, idade, origem ou qualquer diferença social. Os empregados citam que as regras de recrutamento e para remuneração estão registradas e divulgadas nos documentos da organização, e estes estão disponíveis para consulta de todos os empregados. De forma sincrônica, a maioria dos entrevistados desconhece ações voltadas ao compromisso com a equidade racial e de gênero que intencionem reduzir a desigualdade com mulheres ou reduzir o preconceito racial. De acordo com P5, "a empresa poderia promover eventos para conscientização do preconceito racial e a desigualdade social com as mulheres". No entanto, os participantes informam também que não percebem, na organização, tratamento diferenciado por parte desta aos empregados em razão de gênero ou questões raciais.

Quanto ao indicador política de remuneração, benefícios e carreira, a opinião dos participantes foi bem dividida, pois quando foram perguntados quanto ao plano de carreira, cargos e salários e a importância deste, houve quem afirmasse que a organização oferece um plano bem estruturado, bem como surgiram opiniões contrárias, que consideram que com o plano de carreira oferecido, as oportunidades de crescimento são limitadas e desiguais, principalmente quando se trata de cargos a partir da gerência. Isso tem sido um dos problemas delimitados por Dutra (2009), quando se trata da realidade brasileira.

Quando perguntados se a empresa possui ações para cuidar da saúde, segurança e condições de trabalho de seus empregados, todos os participantes afirmaram positivamente. Segundo Marras (2005), o zelo nesta subcategoria protege a organização de muitos encargos. Entre os programas e ações desenvolvidos pela empresa, foram citados o ora estudado Programa Empresa Saudável, além de ações como ginástica laboral, programa contra o tabagismo, palestras, entre outros. Porém, alguns participantes se mostraram desapontados com o fato de a operadora cobrar coparticipação de seus próprios empregados no plano de saúde, sendo que P4, inclusive, usou a expressão "a casa é de ferreiro, mas o espeto é de pau".

O incentivo à capacitação foi reconhecido de forma unânime. A empresa oferta cursos e palestras aos seus empregados, sejam cursos voltados às funções laborais ou ao desenvolvimento pessoal. Neste quesito houve destaque para cursos que são ministrados pelos próprios empregados ao restante da equipe, e para o auxílio-educação, através do qual a empresa arca com parte dos custos da realização de curso superior, pós-graduação ou curso de língua estrangeira. Sobre isso, P2 comenta: “[...] todos os anos a empresa oferece vários cursos e palestras para aumentar o nível de conhecimento dos colaboradores". P4 complementa afirmando que a organização "está sempre apoiando a capacitação, seja com cursos ou com bolsa de estudos. Constantemente alerta para a importância da qualificação como suporte e 
empregabilidade". Tal posicionamento tem sido uma relevante tendência observada em organizações prestadoras de serviço (MILKOVICH; BOUDREAU, 2000).

Ao se investigar o comportamento da organização frente às demissões, grande parte dos entrevistados comentou que já presenciaram demissões realizadas pela empresa como forma de redução de custos, mas que hoje essa não é uma prática aplicada com frequência. Quanto à empresa utilizar sua influência para realocar empregados demitidos no mercado de trabalho, a maior parte dos participantes informou desconhecer ações neste sentido, que esta não é uma prática comum da organização.

Também não demostraram conhecer algum programa para preparação do empregado para a aposentadoria, visando a reduzir o impacto dessa nova condição nos rendimentos financeiros. Os entrevistados informaram que além de cumprir as obrigações legais quanto à aposentadoria de seus empregados, não percebem outras ações da empresa para tratar as consequências da aposentadoria na vida de seus empregados. A despeito da trajetória profissional rescindir diante de demissões e aposentadoria, acredita-se que seja de fundamental importância no cenário das organizações e da sociedade de modo geral (DUTRA, 2005).

Assim, depreende-se a existência de indicadores significativamente trabalhados como desenvolvimento pessoal, e outros nem tanto, como a relação da organização com o sindicato.

\section{A qualidade de vida no trabalho}

A categoria de análise qualidade de vida no trabalho foi investigada por meio dos indicadores do modelo proposto por Walton (1973).

Todos os participantes da pesquisa informaram que a organização oferece benefícios além do salário, como plano de saúde, plano odontológico, vale-alimentação, vale-refeição, e auxílio-educação e auxílio-creche para empregadas que são mães. No que se refere à coerência dos salários oferecidos pela empresa aos empregados, a maioria dos participantes considera que o salário que recebe está de acordo com a média oferecida pelo mercado. No entanto, quando comparado o salário que o participante recebe em relação às funções exercidas e ao salário dos demais empregados, a maioria considera que seu salário não é compatível. Os participantes informam que o salário oferecido pela organização não é compatível com o nível de exigência de suas funções e ainda percebem há discrepâncias salariais entre as diferentes funções existentes dentro da empresa, tendo em vista o nível de complexidade de uma função para outra. A carreira segue a mesma linha, já que a partir de um determinado tempo já não se tem opção de transposição na trajetória profissional (DUTRA, 2005).

No que se refere ao desenvolvimento pessoal, a maioria dos participantes afirmou que, em relação ao desenvolvimento de capacidades, a empresa oferece oportunidades. Os participantes citaram como ações específicas o Programa Mentor, o Seminário de Ingresso e o programa de capacitação onde os próprios empregados ministram cursos aos demais, transmitindo conhecimentos que possuem em determinadas áreas. Através desta última ação, "o colaborador que desenvolve alguma habilidade, e esta é necessária e útil para os outros funcionários, ele pode apresentar e ensinar em algumas aulas programadas" (P10). Contudo, o participante P14 comentou que "parece que todos os treinamentos são para nos adestrar a trabalhar mais e fazer o que a [...] [organização] quer", o que evidencia a percepção por parte 
dos empregados de que os treinamentos também se manifestam como uma forma de controle organizacional (ROCKENBACH et al, 2013).

Quanto às condições de trabalho oferecidas pela empresa, as físicas, materiais e de segurança são consideradas adequadas, sendo oferecidos, inclusive, equipamentos ergonômicos adequados; todavia, os empregados são expostos a um alto nível de estresse. Essa afirmação pode ser ilustrada pela fala da P12: "Tento enfrentar durante o dia a dia, que às vezes gera rotina, pois a atividade que exerço é muito repetitiva, sendo isso o maior causador do meu estresse. Procuro observar os problemas de forma tranquila [...]". Assim, nota-se que o estresse tem representado um dos maiores desafios da área de recursos humanos na contemporaneidade (MARRAS, 2005).

Sobre a integração social, constatou-se uma integração entre colegas e que o trabalho em equipe é um fator muito importante. Não é perceptível a existência de preconceitos por parte de gestores e colegas dentro da empresa, indo ao encontro do que elenca Walton (1973).

Acerca de relação trabalho e espaço total de vida, a maioria dos participantes possui jornada de trabalho de 8 horas e 48 minutos e consideram a carga horária compatível com a função exercida dentro da organização. Apesar disso, a maioria dos entrevistados acrescentou algum comentário de que considera a carga horária cansativa, dificultando a realização de outras atividades inerentes à totalidade do ser humano, em outras dimensões fora da organização (RAMOS, 1989).

Convergindo com o que foi idealizado pelo modelo teórico de Walton, as pessoas comentaram, enfaticamente, que os gestores da organização se mostram cautelosos no que tange ao constitucionalismo, e os responsáveis pelos aspectos legais e contábeis têm sido bem qualificados e desenvolvidos para tal.

Em se tratando da relevância social da vida no trabalho, a maioria acredita que a organização possui responsabilidade com a comunidade, mas, com os empregados, limita-se a desenvolver o necessário previsto em lei. Alguns dos entrevistados manifestaram um sentimento de devoção às oportunidades oferecidas pela organização, sendo que foi por meio dela que conseguiram pagar seus estudos, comprar suas casas etc. Um dos entrevistados, de modo expressivamente exclamativo comentou: "Não sei o que será da minha vida sem a [...] [organização]. Eu vivo para isso aqui, meu Deus!" (P15). Por outro lado, conforme P12, "a qualidade nos serviços realizados, pelo feedback de clientes externos, não é bem vista. Existem muitas reclamações referentes aos planos oferecidos e marcação de consultas [...]" - o que faz crer que deveria ser dada mais atenção às sinalizações dos clientes externos.

\section{As coerências e as incoerências existentes na relação entre a responsabilidade social e a qualidade de vida no trabalho}

No confronto entre as categorias responsabilidade social com o público interno e qualidade de vida no trabalho foi possível pontuar algumas coerências e incoerências. Dentre as várias relações que podem ser estabelecidas, foram eleitas para reflexão dois entrelaçamentos coerentes e quatro incoerentes.

Os dados revelaram que a dificuldade nas negociações entre o sindicato e a classe patronal da organização deve-se a uma política de treinamentos reconhecida como 
predominantemente comportamental e também a uma gestão participativa que, apesar de favorecer a manifestação de opiniões em várias esferas, considera efetivamente somente as pertinentes ao âmbito operacional.

A outra coerência evidenciada foi que os dados referentes aos quesitos valorização da diversidade e compromisso com a equidade racial e de gênero estão consoantes com a subcategoria integração social. Conforme os dados, os empregados sentem-se à vontade entre colegas de trabalho e apontaram isso como fator positivo e mitigador do nível de estresse, e foram firmes ao expressar que não observam práticas discriminatórias no contexto da operadora.

Por outro lado, uma das incoerências percebidas foi que embora a relação com os empregados terceirizados seja salutar, estes têm adquirido responsabilidades que não competem a eles, o que pode acarretar o comprometimento da qualidade de vida no trabalho em termos de constitucionalismo.

Embora tenha sido explicitada a percepção de lógica de treinamento behaviorista, os participantes registraram que a organização incentiva de modo intenso o desenvolvimento de seus empregados. Entretanto, a despeito disso, muitos deles também afirmaram que a trajetória profissional acaba sendo curta, o que leva a crer que a política de carreira não comporta o aproveitamento de todas as potencialidades desenvolvidas por meio do treinamento.

São feitos investimentos nas condições físicas e materiais de trabalho, mas o nível de estresse foi considerado alto por doze dos quinze entrevistados, o que supostamente advém da natureza das tarefas desenvolvidas. Além disso, vários participantes se mostraram inconformados com a cobrança de coparticipação no plano de saúde, já que este serviço é prestado pela própria organização.

As subcategorias comportamento frente a demissões e preparação para a aposentadoria merecem uma atenção significativa, se confrontadas com os dados acerca da relevância social do trabalho. Os empregados fazem da organização uma extensão dos seus lares e vêem naquele espaço a sua identificação pessoal, sendo que alguns comentam que literalmente não saberiam o que fazer da vida se fossem demitidos ou se aposentassem. Essa fobia pode ser mitigada por meio de programas que os preparem para etapas previsíveis da vida, como a aposentadoria, ou até mesmo as incertas, como o desligamento.

Tanto a categoria responsabilidade social com o público interno quanto a qualidade de vida no trabalho apresentaram-se satisfatórias, sendo que alguns quesitos convergiram com o que preconizam os modelos sugeridos (Instituto Ethos e Walton), e, outros, não.

\section{CONSIDERAÇÕES FINAIS}

Com base no referencial teórico e nos métodos utilizados, esta pesquisa buscou analisar a relação entre a responsabilidade social e a qualidade de vida no trabalho dos empregados de uma operadora de planos de saúde de Florianópolis.

Muitos estudos organizacionais têm sido desenvolvidos sob a ótica da responsabilidade social e sob a ótica da qualidade de vida no trabalho, de forma autônoma. Neste trabalho, a ideia foi mapear os dados e estabelecer um entrelaçamento nas duas perspectivas, para que fosse possível perceber se aquilo que pretensiosamente se busca em termos de responsabilidade social efetivamente favorece a qualidade de vida no trabalho. 
A organização, como já se tinha a expectativa em função de sua história, foi um objeto de estudo de tamanha riqueza, que permitiu nitidamente a identificação das diversas subcategorias que os pesquisadores se propuseram a investigar.

À luz dos dados obtidos, identificou-se que as práticas da organização aparentemente estão voltadas ao desenvolvimento da qualidade de vida no trabalho; no entanto, há fatores que precisam ser ajustados para que as intenções estratégicas da organização sejam colocadas em prática.

Dentre as fragilidades observadas, depreende-se que seria interessante: estabelecer uma relação mais próxima com o sindicato da categoria, de modo a promover um maior favorecimento aos interesses dos empregados; desenvolver ações para auxiliar os empregados demitidos a se recolocarem no mercado de trabalho, por meio de formas alternativas de reingresso; capacitar os empregados para lidarem com a fase da aposentadoria; promover equiparação interna salarial realizando, inicialmente, uma análise de cargos para verificar as discordâncias entre os níveis salariais e as responsabilidades dos cargos; desenvolver ações para reduzir o nível de estresse dos empregados no exercício de suas funções, proporcionando-lhes um local para descanso nos intervalos do trabalho; e inserir na política salarial a gratificação por desempenho.

Embora tenha sido adotado o rigor científico, é possível que o viés da pesquisadora com vínculo com a operadora tenha se manifestado nas inferências do trabalho. Apesar de esta pesquisa se configurar como estudo de caso, convém ressaltar que a pretensão não era dar conta de todas as possibilidades de análise, mas, sim, induzir o leitor a reflexões acerca de novas práticas organizativas, que possam superar os delineamentos de um remake fordista, de forma promover o bem-estar no mundo do trabalho. Dito isso, advoga-se ser interessante uma agenda de pesquisas futuras que estenda a investigação aos demais eixos do Programa Empresa Saudável.

\section{REFERÊNCIAS}

1. ALBUQUERQUE, L. Competitividade e recursos humanos. Revista de Administração da USP. São Paulo, v. 27, n. 4, p. 16-29, out./dez. 1992.

2. ASHLEY, P.A. A mudança histórica do conceito de responsabilidade social empresarial. In:

3. . Ética e responsabilidade social nos negócios. 2. ed. São Paulo: Saraiva, 2005, p. 44-65.

4. BARDIN, L. Análise de conteúdo. Lisboa, Portugal: Edições 70 LDA, 2009.

5. BÚRIGO, Carla Cristina Dutra. Qualidade de vida no trabalho: dilemas e perspectivas. Florianópolis: Insular, 1997.

6. CORRÊA, Rossi A. A. Qualidade de vida, qualidade no trabalho, qualidade do atendimento público e competitividade. Revista de Administração Pública, Rio de Janeiro, v. 27, p.113-123, jan. 1993.

7. DENZIN, NK; LINCOLN, YS (editors). Handbook of qualitative research. Thousand Oaks: Sage Publications, 1994. 
8. DIAS, R. Marketing ambiental: ética, responsabilidade social e competitividade nos negócios. São Paulo: Atlas, 2007.

9. DUTRA, J. Gestão de carreiras na empresa contemporânea. São Paulo: Atlas, 2009.

10. FERNANDES, E.C. Qualidade de vida no trabalho. 2. ed. Salvador: Casa da Qualidade, 1996.

11. FREDERICK, W. The growing concern over business responsibility. California Management Review, n. 4, v. 2, p. 54-61, 1960.

12. FREIRE, R.; SOUZA, M. J. B.; FERREIRA, E. Responsabilidade social corporativa: evolução histórica dos modelos internacionais. In: Simpósio de Excelência em Gestão e Tecnologia - SEGeT, 5., 2008, Resende. Anais... Resende: SEGeT, 2008. p. 1-16.

13. FRIEDMAN, M. The social responsibility of business is to increase its profits. New York Times Magazine, 1970. Disponível em:

14. <http://www-rohan.sdsu.edu/faculty/dunnweb/rprnts.friedman.dunn.pdf $\geq$. Acesso em: 01 jun 2010.

15. GARAY, A. B. B. S. Programa de voluntariado empresarial: modismo ou elemento estratégico para as organizações? Revista de Administração, São Paulo n. 3, v. 36, p. 6-14, Jul-Set 2001. Disponível em: <www.rausp.usp.br/download.asp?file=v3603006.pdf>. Acesso em: 14 ago 2010.

16. GIL, A. C. Gestão de pessoas: enfoque nos papéis profissionais. São Paulo: Atlas, 2001.

17. GOMES, A.; MORETTI, S. A responsabilidade social: uma discussão sobre o papel das empresas. São Paulo: Saraiva, 2007.

18. INSTITUTO ETHOS. Ética e qualidade nas relações. São Paulo, 2009. Disponível em: <http://www.ethos.org.br/docs/conceitos_praticas/indicadores/responsabilidade/etica.asp >. Acesso em: 18 maio 2010.

19. KARKOTLI, G. Fundamentos da responsabilidade social. Curitiba: Camões, 2008.

20. MARRAS, J. P. Administração de recursos humanos: do operacional ao estratégico. 10. ed. São Paulo: Futura, 2005.

21. MELO NETO, F. P.; FROES, C. Responsabilidade social e cidadania empresarial: a administração do terceiro setor. 2. ed. Rio de Janeiro: Qualitymark, 1999.

22. . Gestão da responsabilidade social corporativa: o caso brasileiro. Rio de Janeiro: Qualitymark, 2001.

23. MILKOVICH, G.; BOUDREAU, J. Administração de recursos humanos. São Paulo: Atlas, 2000.

24. MISOCZKI, M. Das práticas não-gerenciais de organizar à organização para a práxis da libertação. In.: MIZOCZKI, M., FLORES, R., MORAES, J. (Org). Organização e práxis libertadora. Porto Alegre: Dacasa Editora, 2010.

25. PAULA, A. P. P. Tragtenberg revisitado: as inexoráveis harmonias administrativas e a burocracia flexível. RAP: Revista de Administração Pública, Rio de Janeiro, v. 36, n. 1, p. 127-144, jan./fev. 2002. 
26. POLÍTICA do voluntariado. Florianópolis: [s.n.], 2010. Documento com acesso disponível somente para empregados da operadora de planos de saúde.

27. PONTES, J. Proposta para avaliação do impacto das ações praticadas por uma empresa e sua relação com os indicadores de desempenho. 2007, f. 178. Tese (Doutorado em Engenharia de Produção)-Universidade Federal de Santa Catarina, Florianópolis, 2007.

28. RAMOS, A. G. A nova ciência das organizações. Rio de Janeiro: FGV, 1989.

29. REED, M. In praise of duality and dualism: rethinking agency and structure in organizational analysis. Organization Studies, v. 18, no. 1, p. 21-42, 1997.

30. ROCKENBACH JÚNIOR, P.C et al. Reflexões sobre uma perspectiva crítica na concepção do processo de capacitação dos empregados da Escola Alpha. Revista Gestão e Planejamento, Salvador, v. 13, n. 1, p. 177-198, jan./abr. 2013.

31. RODRIGUES, Marcus Vinícius. Qualidade de vida no trabalho: evolução e análise no nível gerencial. 11. ed. Petrópolis: Vozes, 2008.

32. ROESCH, S. M. A. Projetos de estágio e pesquisa em administração: guia para estágios, trabalhos de conclusão, dissertações e estudos de caso. 2. ed. São Paulo: Atlas, 1999.

33. SOUZA, Janice Janissek de ; BASTOS, Antônio V. Bittencourt. Programas de qualidade de vida no trabalho em contextos diferenciados de inovação: uma análise multivariada. REAd. Revista Eletrônica de Administração, v. 15, p. 2, 2009 . Disponível em: <http://www.read.ea.ufrgs.br/>. Acesso em: 03 out 2010.

34. TENÓRIO, Fernando Guilherme (Org.). Responsabilidade social empresarial: teoria e prática. 2. ed. Rio de Janeiro: Editora FGV, 2004.

35. TREVISAN, Fernando Augusto. Balanço social como instrumento de marketing. Revista de Administração de Empresas Eletrônica, São Paulo, n. 2, v. 1, jul-dez 2002. Disponível em: < http://www16.fgv.br/rae/redirect.cfm?ID=1465>. Acesso em: 21 ago 2010.

36. VELOSO, L.H.M. Ética, valores e cultura: especificidades do conceito de responsabilidade social corporativa. In: ASHLEY, Patrícia Almeida. Ética e responsabilidade social nos negócios. 2. ed. São Paulo: Saraiva, 2005. p. 2-16.

37. VIEIRA, Adriane. A qualidade de vida no trabalho e o controle da qualidade total. Florianópolis: Insular, 1996.

38. WALTON, R. E. Qualitlity of working life: what is this? Sloan Management Review, v. 15, n. 1, Fall, 1973. 